\title{
ethic@ \\ EMOÇÕES E VALORES: \\ UMA ABORDAGEM SENTIMENTALISTA
}

\author{
EMOTIONS AND VALUES: \\ A SENTIMENTALIST APPROACH
}

\author{
LEONARDO DE MELO RIBEIRO ${ }^{1}$ \\ (UFMG/CNPq - Brasil)
}

\begin{abstract}
RESUMO
Neste artigo, uma tese sentimentalista qualificada é formulada para explicar a relação entre emoção e valor, em especial a aquisição de conceitos e de competências valorativas. Esta tese defende, por um lado, que sentimentos são os elementos essenciais para a caracterização de emoções e, por outro lado, que valores devem ser compreendidos em referência a emoções. Duas objeções à tese serão consideradas: as objeções da recalcitrância e da circularidade. Para responder a estas, será defendida a ideia de que sentimentos podem possuir objetos intencionais, juntamente com a ideia de que conceitos valorativos são conceitos de ordem superior sobre condições de adequação de experiências emocionais valorativas. No que diz respeito especificamente à objeção da recalcitrância, argumentaremos que a tese sentimentalista está em melhor situação do que a sua principal rival, a tese judicativa. Por último, mostraremos como o sentimentalista pode explicar níveis de complexidade entre emoções e valores. O resultado final é uma tentativa de mostrar como uma tese sentimentalista pode ser coerente sobre a relação entre emoção e valor.
\end{abstract}

Palavras-chave: emoções; valores; sentimentalismo; meta-ética.

\begin{abstract}
In this paper, a qualified sentimentalist thesis is put forward to explain the relation between emotion and value, in special the acquisition of concepts and evaluative competences. This thesis advocates, on the one hand, that feelings are the essential elements for the characterization of emotions and, on the other hand, that values should be understood by reference to emotions. Two objections are considered: the circularity and the recalcitrance objections. To answer these, the idea that feelings can have intentional objects will be defended, along with the idea that evaluative concepts are higher-order concepts about adequacy conditions of evaluative emotional experiences. As for the recalcitrance objection specifically, we will argue that the sentimentalist thesis is in a better position than its main rival, the judgmentalist thesis. Lastly, we will show how the sentimentalist can explain levels of complexity among emotions and values. The final result is an attempt to show how a sentimentalist thesis may be coherent about the relation between emotion and value.
\end{abstract}

Keywords: emotions; values; sentimentalism; metaethics.

\section{Introdução}


Nos idos da Grande Depressão dos anos 30, F. Roosevelt, em seu discurso presidencial inaugural, conclamou a população norte-americana a superar a crise dizendo memoravelmente que "a única coisa que temos a temer é o próprio medo". Embora o fenômeno psicológico ao qual Roosevelt se referiu seja facilmente reconhecível, ele apresenta uma dificuldade para teorias da emoção e do valor. Afinal, como é possível ter uma experiência emocional persistente, por exemplo, de medo, ainda que se julgue, na mesma circunstância, que não há razões para temer?

Este artigo tomará como mote a frase de Roosevelt e se desdobrará em uma discussão sobre como uma teoria da emoção e do valor seria capaz de explicar aquele fenômeno, que, seguindo a literatura no tema, chamarei de 'problema da recalcitrância'. ${ }^{2}$ De uma perspectiva geral, exploraremos os recursos conceituais que uma versão qualificada de uma tese sentimentalista sobre a relação entre emoção e valor possui para lidar com aquele problema. ${ }^{3}$ Em particular, como uma tese sentimentalista pode responder ao problema e, ao mesmo tempo, evitar a recorrente objeção da circularidade.

Iniciaremos a discussão apresentando o que está basicamente em jogo na pergunta sobre a relação entre valor e emoção. Em um segundo momento-como um passo preparatório para a discussão sobre a tese sentimentalista—faremos um breve percurso por uma tese rival, a tese judicativa. Como desdobramento deste tópico, argumentaremos a favor da possibilidade de uma tese sentimentalista sobre emoções e de sua relação com conceitos e juízos valorativos. Terminaremos a discussão qualificando tal tese sentimentalista, apresentando um modelo esquemático para explicar relações de complexidade entre vários tipos de emoções e valores (em especial, emoções e valores morais).

\section{Emoções e valores}

É inegável que haja relações relevantes entre emoções e valores. Reconhecer isso não implica defender que tais relações sejam todas da mesma natureza, nem que a análise de um conceito ('emoção' ou 'valor') esgote-se na análise do outro, nem que uma única caracterização tanto de valor quanto de emoção esteja disponível para esclarecer qualquer relação entre todos os tipos de valores e de emoções, nem mesmo que todos os valores 
estejam relacionados a emoções. Nada do que diremos aqui dependerá de uma defesa dessas teses mais robustas sobre a relação entre valor e emoção. Basta, para nossos propósitos, reconhecer que há uma relação sistemática entre valores e emoções, no sentido de que há um padrão explicativo e conceitual identificável entre estes. No que diz respeito a este aspecto, é uma hipótese substantiva a ser apresentada aqui que tal relação é estreita a ponto de ser constitutiva, em um sentido a ser especificado melhor adiante. Por ora, basta dizer que essa relação constitutiva diz respeito às condições para a aquisição de conceitos e competências emocionais e valorativas.

Assim, feitos esses esclarecimentos, é comum encontrarmos, por um lado, tanto na literatura filosófica quanto na literatura científica (sobretudo da psicologia cognitiva, social e experimental), a ideia de que um elemento fundamental para a individuação de emoções são conceitos e/ou juízos valorativos que as constituem. A lista fornecida pelo psicólogo Richard Lazarus dos objetos de avaliação (appraisals) das emoções é um excelente exemplo. ${ }^{4}$ Em filosofia, Anthony Kenny (fazendo eco a uma distinção escolástica) defende a tese de que toda emoção possui (como uma questão conceitual) um objeto formal específico, que cumpre um papel definidor da emoção, e tal objeto formal é especificado em termos valorativos. ${ }^{5}$ A tese de Kenny é amplamente tomada como um desiderato a ser satisfeito por toda teoria da emoção. ${ }^{6}$ Assim, o objeto formal do medo é aquilo que é perigoso; o da raiva, uma ameaça, uma frustração ou um obstáculo; o da tristeza, alguma perda; o do orgulho, a valorização de algo relacionado ao eu; o da indignação moral, alguma forma de injustiça; etc.

Por outro lado, a defesa da relação inversa - de que valores dependem de emoções-é menos comum; mas não tão incomum. Além da versão sentimentalista supostamente radical de Hume, segundo a qual (aparentemente) todos os valores podem ser compreendidos essencialmente com relação a emoções, não são, de forma alguma, raros os casos de autores que, embora não estejam dispostos a endossar versão de Hume, ${ }^{7}$ reconhecem que emoções cumprem um papel fundamental na compreensão e constituição de vários valores. ${ }^{8}$

Dessa forma, em termos mais específicos, o que está em jogo no debate que nos interessa aqui é saber como explicar a relação entre a aplicação de determinado tipo de conceito valorativo, a formulação do respectivo juízo valorativo, e a emoção associada. 
Por exemplo, a relação entre o que é perigoso e a emoção de medo. Como acabamos de antecipar, existem duas típicas abordagens neste tema: as teses judicativa e sentimentalista. Vejamos, então, estas teses.

\section{A tese judicativa}

A tese judicativa defende a prioridade de conceitos e juízos valorativos (tipicamente de conteúdo cognitivo) sobre emoções, no seguinte sentido: emoções são compreendidas como envolvendo (como parte de seu conteúdo) o juízo de que algo é valoroso em algum aspecto. Assim, segundo essa tese, é parte do conteúdo da emoção de medo o juízo de que algo é perigoso; este juízo constitui (ao menos em parte) e fornece o critério de individuação da emoção de medo. Martha Nussbaum, uma estrênua defensora da posição, diz:

(...) The beliefs on which emotions are based prominently include our evaluative beliefs, our beliefs about what is good and bad, worthwhile and worthless, helpful and noxious. (Nussbaum 1990, 370) ${ }^{9}$

Solomon, um antigo representante da tradição judicativa, diz que: "emotions essentially involve the abilities to conceptualize and evaluate" $(2007,204) .{ }^{10}$ Assim:

The heart of every emotion is its value judgments, its appraisals of gain and loss, its indictments of offenses and its praise of virtue, its often Manichean judgments of "good" and "evil", "right" and "wrong". (Solomon 1976, 269)11

Em função de tal natureza judicativa valorativa, emoções nos “engajam” com o mundo:

(...) emotions are engagements with the world, not mere self-enclosed feelings, and accordingly I have tried to pin this perspective down by insisting, in somewhat 
sloganeering form, that emotions are judgments. I mean by this, of course, that emotions are evaluative judgments (...). (Solomon 2007, 204) ${ }^{12}$

Sobre o medo, Solomon, então, diz que:

(...) fear (...) is an engagement with the world, not just a self-contained "feeling". It is about something that threatens, something that endangers. (...) fear is not fear unless it is about some perceived danger in the world. (Solomon 2007, 32) (13 $^{13}$

A tradição judicativa diverge internamente sobre o papel do juízo na explicação de tal relação. Algumas versões (como as de Nussbaum e de Solomon) parecem sustentar que o juízo valorativo é necessário e suficiente para a emoção (de modo que um pode ser identificado com o outro). ${ }^{14}$ Outras versões sustentam que o juízo é apenas necessário (como precondição ou antecedente causal), mas não suficiente, e admite que outros elementos ocupem um papel acessório na experiência emocional: elementos como sensações, sentimentos, desejos, alterações corporais e fisiológicas (e suas expressões) e padrões comportamentais. ${ }^{15}$ Nestas versões, esses elementos que normalmente acompanham emoções são frequentemente tomados como, por assim dizer, epifenômenos. ${ }^{16}$

Ainda que essas versões da tese judicativa divirjam em seus detalhes, todas concordam no que diz respeito ao juízo valorativo ser o elemento central para a individuação da emoção. E, apesar da relevância das divergências, o mais importante para a nossa discussão aqui é o fato de todas as versões dessa tese defenderem que o elemento propriamente valorativo da emoção é fornecido integralmente pelo juízo.

Uma séria dificuldade com a tese judicativa está relacionada ao fenômeno que usamos como mote inicial. Parece ser um fato empírico trivial sobre nossa psicologia que, por vezes, estamos sujeitos a certas respostas recalcitrantes em um determinado tipo de situação enquanto, ao mesmo tempo, julgamo-las respostas inadequadas. Estamos cientes da resposta inadequada e, ainda assim, somos, por vezes, persistentemente acometidos 
por ela. Dessa forma, como disse Roosevelt, podemos pensar que não há nada a temer, embora sintamos medo. Como o judicativista poderia explicar tal fenômeno?

Não é claro. O judicativista não possui um critério para caracterizar emoções independentemente de juízos valorativos. Se alguém tem a experiência emocional de medo com relação a $\mathrm{X}$, ele deve estar julgando que $\mathrm{X}$ é perigoso. Nussbaum ilustra $\mathrm{o}$ problema de modo cristalino:

[Emotions] themselves have a cognitive content; they are intimately related to beliefs or judgments about the world in such a way that the removal of the relevant belief will remove not only the reason for the emotion but also the emotion itself. The belief is the necessary basis and "ground" of the emotion. It might even be said to be a constituent part of the emotion itself. (...) This implies (...) that [for example, in the case of anger] if I discover that my belief is falsethat the apparent wrong did not in fact take place-I will, discarding my false belief, cease to be angry. If some residual painful feeling does persist, it will not be considered anger any longer but, rather, as residual irrational irritation or excitation. (Nussbaum 1990, 291-2) ${ }^{17}$

Mas é exatamente aqui que está o problema. O que dizer sobre estes resíduos ou excitações irracionais? Eles não seriam manifestações emocionais? Nussbaum defende que tais resíduos ou excitações não são emoções (ou mesmo emocionalmente relevantes). Mas isso soa inteiramente ad hoc. Nosso entendimento comum, baseado em nosso conhecimento compartilhado sobre o fenômeno, sugere que tais resíduos ou excitações são emoções ou estados emocionalmente relevantes. A menos que tenhamos boas razões para revisar este entendimento comum, parece que estamos justificados em preservá-lo e a tomar a resposta de Nussbaum como ad hoc, que parece simplesmente negá-lo.

Não exploraremos as respostas possíveis que o judicativista poderia ter a tal dificuldade. Há candidatos interessantes neste tópico. ${ }^{18}$ Nosso objetivo, ao introduzir a discussão através da tese judicativa, foi sobretudo dialético, como preâmbulo para o cenário no qual o defensor da tese sentimentalista deverá atuar. Mas, por outro lado, como veremos, parece que há vantagens na tese sentimentalista em relação à tese judicativa no 
que diz respeito a fornecer uma resposta ao problema da recalcitrância. Uma vez que o judicativista, por definição, entende emoções como o exercício de capacidades judicativas-e, portanto, sensíveis a relações evidenciais e sujeitas a processos inferenciais - é intrigante saber como um indivíduo pode, em uma mesma circunstância e diante dos mesmos fatos, conscientemente julgar que $p$ e julgar que não- $p$.

\section{A tese sentimentalista}

A tese sentimentalista, tal como entendida aqui, defende que a aquisição de competências conceituais valorativas é dependente de emoções e que emoções são essencialmente constituídas por sentimentos. A tese busca motivação na ideia básica de que não parece fazer sentido falar de valores sem apelar primariamente às nossas respostas subjetivas sentimentais. Há, assim, dois passos na tese sentimentalista: por um lado, explicar como, em direção oposta à tese judicativa, emoções podem constituir (ao menos parcialmente) valores; por outro lado, defender a ideia de que sentimentos são o elemento fundamental para a compreensão de emoções. Há uma relação estreita entre os dois passos. Se emoções são constitutivas de valores, a caracterização de emoções deve ser tal que valores não sejam pressupostos, a fim de se evitar circularidade. Mas, se emoções fossem juízos valorativos (ou parcialmente constituídas por estes), obviamente a análise seria circular. ${ }^{19}$

Vale dizer, porém, a título de breve esclarecimento, que uma teoria das emoções alternativa à tese judicativa poderia seguir passos similares e, ainda assim, não assumir uma forma sentimentalista. Ela poderia, por exemplo, adotar uma versão behaviorista ou uma versão somática (nesta última, como fazem James, Damasio, Prinz, embora de modos diferentes). ${ }^{20} \mathrm{Na}$ primeira versão, emoções seriam essencialmente padrões comportamentais; na segunda, emoções seriam percepções e expressões de alterações corporais e fisiológicas. É plausível sustentar que toda teoria das emoções pode e deve ser sensível às reinvindicações dessas teses alternativas. Provavelmente, uma análise adequada das emoções será complexa e rica a ponto de incorporar, se não padrões comportamentais e corporais fixos, alguma relação com ações e com a percepção e a expressão de modificações corporais. Parece ser típico, por exemplo, da experiência de medo uma disposição para escapar da situação que deflagra a emoção, assim como alterações corporais perceptíveis, como palpitação, sudorese, tremor, arrepios, etc. O 
sentimentalista, em particular, pode admitir isso tudo e talvez permanecer um sentimentalista se defender que todos esses elementos adicionais devem ser permeados e unificados por sentimentos quando estivermos efetivamente falando de emoções-e que nenhum daqueles é suficiente para a individuação das emoções.

O sentimentalista pode, assim, acompanhar Peter Goldie, quando este diz que sem sentimentos, emoções não seriam o que são $(2000,50)$ e que: "without feelingswhatever precisely these might be-emotional experience would be, to say the least, utterly different" $(2009,232)$. Assim, se o sentimentalista for capaz de mostrar que sentimentos cumprem um papel fundamental na individuação de emoções, ele talvez seja capaz de mostrar como sentimentos e, por extensão, emoções, cumprem um papel constitutivo também na explicação de valores. Antes, porém, de discutirmos os detalhes sobre como o sentimentalista poderia explicar emoções em termos de sentimentos, precisamos compreender melhor como a análise de um conceito (e juízo) valorativo poderia ser dada em termos de emoções. Somente assim ficará inteiramente claro por que é fundamental que a caracterização de emoções fornecida pelo sentimentalista não faça referência aos valores que as emoções propõem explicar.

Vale notar que o sentimentalista enfrentaria dificuldades se entendesse a relação entre valores e emoções de modo tão estreito a ponto de reduzir valores diretamente a emoções. Neste sentido, ele não estaria em posição melhor do que o judicativista para responder ao problema da recalcitrância. O sentimentalista pode, porém, evitar isso se propuser uma análise indireta, não-reducionista, de conceitos e juízos valorativos em termos de emoções, da seguinte forma:

Julgar que Xé perigoso é julgar que é adequado sentir medo diante de X.

Esta análise de um conceito valorativo (perigoso), embora não seja integralmente dada em termos de emoções, mostra como emoções (entendidas como sentimentos) cumprem um papel fundamental na especificação do valor (e do juízo valorativo), mas sem propor uma redução direta de conceitos valorativos a emoções. Há, no analisans da proposta, a referência ao conceito 'adequado', que cumpre um papel, por assim dizer, "normativo". 
Isso significa que nem todas as manifestações de medo serão adequadas como resposta. Assim, os critérios de especificação daquilo que é adequado envolverão, inter alia, referência a condições normativas para a identificação daquilo que é perigoso. Neste sentido, a análise não é normativamente "neutra" ou redutiva, pois não será possível identificar aquilo que é adequado sobre o perigo sem, de algum modo, já recorrer ao conceito 'perigoso'. Mas a análise pode, ainda assim, ser dita informativa, pois faz referência ao sentimento de medo que está na base da especificação daquilo que é perigoso. E é neste sentido que o modelo é um modelo sentimentalista. Se, por outro lado, não for possível especificar o sentimento de medo sem pressupor o juízo valorativo de que algo é perigoso, a análise seria circular em um sentido vicioso e, portanto, inaceitável. É neste sentido de circularidade, que diz respeito à caracterização do sentimento que figura na análise sentimentalista de um conceito ou juízo valorativo, que estamos interessados em nossa discussão aqui-e não em uma possível "circularidade" em outro sentido, que diz respeito ao conceito normativo de adequação que, como resultado, gera uma análise não-redutiva. ${ }^{21}$

Deve-se também notar que, naqueles termos, a análise é neutra entre possíveis teses ontológicas e semânticas antagônicas. Aquilo que está na base do que é tomado como adequado (ou que é constitutivo dos critérios de adequação) pode ser uma atitude não-cognitiva, uma atitude cognitiva de resposta a uma propriedade natural ou nãonatural de alguma suposta relação de adequação, o resultado de algum processo construtivista idealizado sobre aquilo que é adequado ou o resultado de alguma prática contextualista, etc. ${ }^{22}$ Assim, no modelo de análise proposto, embora o juízo sobre critérios de adequação seja compatível com teses ontológicas e semânticas distintas, o modelo seria, ainda assim, sentimentalista, uma vez que a referência a sentimentos é um elemento primário e ineliminável da análise.

Tendo visto como o sentimentalista deve proceder em sua análise de valores em termos de emoções, resta, agora, voltarmo-nos especificamente para a teoria das emoções e discutirmos em mais detalhes como emoções podem ser caracterizadas essencialmente em termos de sentimentos.

\section{Emoções como sentimentos}


Em sua defesa de que sentimentos são o elemento essencial para a caracterização de emoções, o principal desafio para o sentimentalista é explicar como sentimentos são compatíveis com intencionalidade, isto é, com aquela característica que a experiência emocional possui de ser direcionada ou ser sobre algo, tipicamente algo no mundo.

Assim, uma versão qualificada de sentimentalismo, que seja capaz de acomodar intencionalidade, deve fornecer uma explicação de sentimentos diferente daquela fornecida pelos modelos de Hume e de William James (ou, pelo menos, como estes modelos são normalmente lidos). Embora a história de Hume seja complexa, ele defende que (ao menos algumas) emoções podem ser individuadas introspectivamente, através de uma fenomenologia característica dos sentimentos. Para James, emoções são sensações associadas a percepções de alterações corporais. Desse modo, Hume e James parecem não encontrar espaço para a intencionalidade das emoções e sua relação com o mundo. Talvez se concedêssemos que é possível falar de intencionalidade sem pressupor conteúdo semântico ou objeto proposicional, emoções poderiam ter estados internos como seus objetos intencionais: a percepção da ocorrência de um sentimento ou de algum estado corporal. Porém, mesmo que se concedesse isso, ainda seria necessário explicar como emoções são, nos termos de Solomon, engajamentos com o mundo.

Uma saída para o sentimentalista seria adotar o modelo proposto por Goldie. Goldie defende que sentimentos são elementos essenciais de emoções e que há dois tipos de sentimentos: sentimentos corporais (sensações) e sentimentos direcionados ao mundo. Para Goldie, ambos estão presentes em emoções, mas sentimentos corporais são insuficientes para a individuação de emoções. Sentimentos corporais podem, porém, "absorver" (nos termos próprios de Goldie, "tomar emprestados") os estados de coisas que são objetos dos sentimentos direcionados ao mundo, de tal modo que ambos os sentimentos convirjam. (Uma dor no peito, embora um sentimento direcionado a um estado interno do organismo, pode se tornar uma dor de medo, quando ela é a manifestação corporal consequente a um sentimento de medo direcionado ao mundo.) Como enfatizamos acima, é plausível supor que sentimentos corporais tenham uma parcela importante na caracterização de emoções. Mas, dadas as restrições que envolvem a nossa tarefa aqui, concentraremos nossos esforços nos sentimentos direcionados ao mundo e apenas pressuporemos, seguindo Goldie, que sentimentos corporais devem fazer 
parte de uma teoria completa das emoções (sem, contudo, especificar qual o papel e a natureza dos mesmos).

Os sentimentos direcionados ao mundo, diz Goldie, possuem um objeto intencional (ainda que não necessariamente proposicional, pois eles podem, por exemplo, ser direcionados a uma pessoa ou objeto), que é algo no mundo:

Feeling towards is thinking of with feeling, so that your emotional feelings are directed towards the object of your thought. So, for example, if I feel disgusted by the pudding, my feelings of disgust are directed towards some perceived or imagined property or feature of the pudding — its sliminess, perhaps — which I apprehend as disgusting. (Goldie $2000,19)^{23}$

Assim,

When an emotion is directed towards its object, then this is a sort of feeling towards the object. The object can be a thing or a person, a state of affairs, or an action or event: when you fear the lion, the object of your fear is a thing, which has certain determinate properties (sharp teeth, perhaps), that will explain why you fear it. (Goldie 2002, 240) ${ }^{24}$

Essa não é uma ideia nova. Na literatura pós-Jamesiana, a maior parte daqueles que defendem que emoções são essencialmente sentimentos, entendem que estes são direcionados a algo no mundo. E, tal como Goldie, que esses sentimentos são primariamente de ordem fenomênica e irredutivelmente subjetivos. Isso não significa, porém, que os mesmos, embora acessíveis diretamente apenas da perspectiva de primeira pessoa, não possam ser identificados e discursivamente articulados da perspectiva de terceira pessoa. Goldie explica o ponto dizendo que: 
(...) to know what someone is feeling, one does not need-which is impossible-somehow to share his unique, immediate and "privileged" method of access; all one needs to be able to do is answer the question, "What is he feeling?" (Goldie 2002, 240) ${ }^{25}$

Assim,

When we think of feelings, and recognise them as what they are, we are deploying a common set of concepts, shared with others, and we can as well think and talk of how another is feeling as we can think and talk of how we are feeling. (Goldie 2002, 240) ${ }^{26}$

Dessa forma, embora sentimentos direcionados a algo no mundo sejam fenomenais e irredutivelmente subjetivos, eles possuem intencionalidade, o que permite que articulemos e compartilhemos nossas experiências sentimentais. Estes sentimentos são, assim, individuados não meramente por seu caráter fenomenológico, mas sobretudo por seus objetos intencionais. Nas palavras de Goldie:

For each sort of emotion, there will be a broadly characteristic qualitative nature of these feelings. But individual emotional experiences can vary widely in how they feel. Any suggestion that our emotional feelings towards things can be understood as, or analysed into, simple terms (such as attraction or aversion, pleasure or distress, feeling comfortable or uncomfortable, positive or negative evaluation on some rating scale) should be strongly resisted. (Goldie 2000, 19) ${ }^{27}$

Essa história sobre a intencionalidade de sentimentos é, Goldie admite, algo esquemático. Mas, para os nossos propósitos aqui, vale dizer que, se o sentimentalista pretende fornecer uma tese plausível das emoções como sentimentos, ele deve ser capaz de fornecer uma caracterização de sentimentos que garanta intencionalidade. Obviamente, muito mais precisaria ser dito sobre conteúdo mental e semântico e sobre a estrutura dos objetos intencionais de tais estados de sentir direcionados ao mundo. Mas, pressupondo que tal 
projeto seja factível, podemos avançar em nossa tarefa de formular uma versão qualificada de sentimentalismo. ${ }^{28}$

Como deve estar claro, esse modelo sentimentalista não exclui o exercício de capacidades cognitivas na constituição e identificação de emoções. Esta é uma razão por que a dicotomia entre cognitivismo e não-cognitivismo em teoria das emoções parece ser pobre e enganadora. Para experenciar um sentimento direcionado ao mundo, é necessário que percepção e crença (e possivelmente passos inferenciais) estejam em cena previamente-e é obviamente possível estender o cenário para casos de exercício de memória e imaginação como antecedentes cognitivos de sentimentos. O que é importante para o sentimentalista qualificado que estamos projetando é preservar o caráter nãovalorativo de tais exercícios de cognição. (Voltaremos a este ponto.)

Algo distintivo no modelo de Goldie (e particularmente importante para o que estamos argumentando) é sua defesa de que emoções não são apenas cognições acrescidas de sentimentos. Sentimentos, para Goldie, transformam nossa relação com o mundo e o conteúdo de nossa percepção e pensamento sobre o mundo. Goldie ilustra o ponto através de um experimento de pensamento (inspirado no famoso caso cunhado por Frank Jackson). Irene é uma gélida cientista que sabe tudo sobre as propriedades do gelo e sabe, em particular, dos riscos que há em caminhar sobre uma camada de gelo de uma determinada espessura (que ela pode cair, se ferir, fraturar ossos, congelar, morrer, etc.). Goldie defende que, embora Irene saiba, em certo sentido, que é perigoso caminhar no gelo, Irene não sabe que caminhar no gelo é perigoso em um sentido emocional. Um dia, então, Irene inesperadamente cai ao caminhar sobre o gelo. Irene sente medo pela primeira vez. (Suponha, claro, um tanto artificialmente, que Irene nunca tivesse sentido medo antes; por isso ela é uma gélida cientista.) Goldie defende, então, que Irene agora tem uma experiência totalmente nova do mundo. Ela adquire um novo conceito, primariamente fenomenal, que não possuía antes: o conceito de "perigo-emocionalmentecarregado" por sentir medo. Para Goldie:

Now (...) Irene is able to perceive, and to think of, the ice in a new way. Her belief, "this ice is dangerous," although perhaps verbally expressed in the same way as before, is now a belief with a different content. Moreover, before she believed that the ice is dangerous 
without feeling; now, she believes it with feeling — with feelings of fear. So there is both a change of attitude and a change of content. (Goldie 2009, 234) ${ }^{29}$

Essa transformação no significado de 'perigoso' é o que caracteriza o conteúdo da experiência emocional através da introdução do sentimento associado. Não é o caso que Irene possui agora um sentimento em relação ao gelo meramente acrescido ao seu conceito anterior de perigo (puramente teórico, segundo Goldie) aplicado ao gelo. A nova maneira de experenciar o mundo transforma a anterior de tal modo que não pode ser decomposta na experiência anterior, acrescida de algo independente. O resultado é uma espécie de "amálgama", em que o todo da experiência é agora diferente e indivisível.

O nosso sentimentalista pode, em larga medida, se apropriar deste modelo. Em particular, o sentimentalista pode acompanhar Goldie em sua tese da alteração de significado e do conteúdo da experiência através da distinção entre a apreensão puramente cognitiva, não-sentimental, e a apreensão sentimental (emocionalmente carregada) do mundo. Mas o nosso sentimentalista poderia também dar um passo além (algo que, devese deixar claro, Goldie não faz): propor que aquilo que distingue aqueles dois momentos (isto é, os dois conteúdos da experiência) é, por um lado, uma apreensão meramente descritiva e valorativamente neutra do mundo-e, portanto, um uso do conceito 'perigo' com significado puramente descritivo - e, por outro lado, uma apreensão valorativa do mundo, tornada possível com a presença do sentimento. O resultado é uma amálgama de cognição e sentimento, que constitui uma experiência valorativa emocional. ${ }^{30}$

Dessa forma, ao acompanhar Goldie na afirmação de que o sentimento transforma a apreensão cognitiva do mundo, o sentimentalista não precisa dizer que a antiga maneira (cognitiva) de descrever o mundo tenha se perdido. Ela permanece disponível; mas o que a nova maneira revela é que a experiência descritiva anterior não era uma experiência valorativa. O sentimentalista poderia agora distinguir conceitualmente uma apreensão cognitiva do mundo, em termos puramente descritivos, neutros valorativamente, e uma apreensão que envolve tanto descrição quanto valoração, cognição e sentimento- e que, ao passar a experenciar o mundo emocionalmente, já não há mais distinção, de um ponto de vista fenomenológico e de seu conteúdo, entre descrição e valoração: o mundo passa a ser visto de modo emocional e valorativamente carregado. Isso permite agora ao 
sentimentalista pleitear que o elemento sentimental não apenas é o elemento que transforma a apreensão puramente cognitiva do mundo em uma experiência emocional, mas também o elemento que introduz uma perspectiva valorativa ao mundo. ${ }^{31}$

\section{Qualificando a tese sentimentalista}

Há duas questões que o nosso sentimentalista precisa ainda esclarecer: se há um significado puramente descritivo de 'perigo' e se sentimentos que tornam a experiência emocional valorativa não são, eles mesmos, juízos valorativos.

É possível falar de perigo de modo não-valorativo? Parece que sim. Antes de cair no gelo, Irene meramente descrevia aquilo que podemos considerar como sendo as propriedades realizadoras do perigo (que é uma propriedade, diga-se de passagem, multiplamente realizável). Isso é algo que um indivíduo é capaz de apreender por processos puramente cognitivos. Ele deve ser capaz de identificar no mundo situações que envolvem risco a ele (e a outros) e distinguir estas situações de uma situação que não envolve risco, e de uma situação que envolve um obstáculo, ou satisfação de um objetivo, etc. ${ }^{32}$ Isso não precisa ser, ainda, engajar-se valorativamente com o mundo, mas simplesmente identificar sua base em termos de propriedades naturais, factual e descritivamente. Isso porque pode ser plenamente possível que alguém diga que uma situação é perigosa por ter todas aquelas propriedades, no sentido descritivo, e não sentir nada associado. Em tal situação, o sentimentalista deve dizer que esse indivíduo é capaz de identificar descritivamente situações de perigo, mas que, ao não sentir medo em nenhuma delas, não apenas não possui uma experiência emocional (como defende Goldie), mas também não se engaja de maneira valorativa com o mundo.

Podemos agora ver em que sentido o nosso sentimentalista pode acomodar um tema tradicional em teoria das emoções que mencionamos acima. Dissemos que é um desiderato de qualquer teoria acomodar a tese de Kenny segundo a qual emoções possuem objetos formais. O nosso sentimentalista pode agora, diferentemente de vários outros da mesma tradição, admitir que toda emoção possui um objeto formal, que serve de base para sua individuação: o perigo é o objeto formal do medo. O medo não poderia ser identificado apenas por sua fenomenologia ou por um conjunto de alterações corporais, 
mas porque envolve um engajamento com o mundo que é dado através de seu objeto intencional. $\mathrm{O}$ que o sentimentalista precisa negar é que tal objeto formal (intencional) seja caracterizado em termos valorativos. Assim, para o sentimentalista, o objeto formal do medo é uma descrição não-valorativa do perigo.

O sentimentalista pode, assim, dizer que o conceito de perigo é necessário formal e abstratamente para individuarmos a emoção de medo. Isso não significa, porém, que há aqui uma circularidade viciosa. O sentimento de medo não envolve, para sua instanciação e para constituir uma experiência valorativa, a aplicação do conceito de perigo em um sentido valorativo. O sentimento de medo transforma uma pura cognição em uma experiência valorativa. O próprio sentimento ou emoção não é um juízo valorativo. É apenas uma perspectiva de segunda-ordem que propriamente introduzirá o conceito de perigo (e o juízo associado) em um sentido valorativo, pois é somente desta perspectiva que são formulados juízos de adequação sobre experiências emocionais (isto é, experiências valorativas básicas). Assim, podemos formular uma versão qualificada da tese sentimentalista:

Julgar que Xé perigoso é julgar que é adequado sentir medo em relação a X; em que sentir medo é caracterizado através de seu objeto formal, perigo*.

'Perigo*' não é um conceito valorativo, nem envolve um juízo valorativo. 'Perigo*' é um conjunto de propriedades que têm relação com risco, dano, ameaça, etc. e que serve formal e abstratamente para individuar uma reação sentimental a tal conjunto de coisas como um sentimento de medo. ${ }^{33}$

\section{Emoções de ordem superior}

A história sentimentalista que vimos contando concentrou-se na relação direta com objetos, indivíduos ou estados de coisas no mundo. No caso do medo, nosso exemplo prototípico, o indivíduo reage sentimentalmente a um conjunto de descrições (nãovalorativas) do mundo, relacionadas a riscos, etc. É apenas quando o indivíduo tem essa reação sentimental que ele propriamente tem uma experiência valorativa. Porém, essa 
história pode dar a impressão de ser capaz de lidar apenas com formas primitivas de medo e não ser capaz de lidar com variações de medo que envolvam níveis mais elevados de complexidade. O mesmo talvez possa ser dito de outras emoções (tipicamente tomadas como básicas) como raiva, alegria, tristeza, surpresa. ${ }^{34} \mathrm{Em}$ suas formas primitivas, essas emoções e suas respectivas experiências valorativas podem ser explicadas em termos da tese sentimentalista que apresentamos acima. Essa história pressupõe que um indivíduo inicia sua aquisição de competências valorativas através de suas reações emocionais (sentimentais) básicas em suas interações diretas com o mundo (que estão provavelmente relacionadas a necessidades vitais). Mas ainda não é claro que o mesmo possa ser dito sobre versões mais complexas das mesmas experiências emocionais.

Além disso, o que dizer sobre emoções (e seus respectivos valores) como orgulho, indignação, culpa, vergonha, inveja, etc.? Essas emoções parecem depender não apenas de níveis mais elevados (qualitativos e quantitativos) de cognição, mas parecem também depender, em tais processos cognitivos, do recurso a conceitos e/ou juízos valorativos. Mas se isso é o caso, não haveria um problema para a tese sentimentalista, já que esta explica valores com referência a emoções, e não o contrário?

As formas primitivas de emoções como medo, raiva, etc., podem envolver pouca sofisticação cognitiva. Elas podem envolver respostas rápidas, automáticas, de curta duração, possuírem uma fisiologia e expressões musculares características (em especial, faciais) e ser resultado de um processo evolutivo adaptativo. ${ }^{35}$ De acordo com a nossa tese sentimentalista, essas emoções já representariam experiências valorativas básicas ou primitivas. Mas isso não implica ainda que os indivíduos que as experimentam já possuam conceitos valorativos e, por extensão, sejam capazes de juízos valorativos. ${ }^{36}$ À medida que estes indivíduos são capazes de maior complexidade cognitiva, sobretudo na forma de exercícios de reflexão (algo tornado possível provavelmente pelo desenvolvimento de linguagem), eles passam a poder fazer uso de conceitos e formular juízos valorativos (refletindo nas condições de adequação das suas experiências valorativas básicas). Eles agora podem não apenas refletir sobre as condições de suas experiências de medo, raiva, etc., mas também redirecionar as experiências características de medo, raiva, etc., a outros objetos, indivíduos ou estados de coisas no mundo. Assim, tal movimento reflexivo pode estender as condições iniciais deflagradoras de medo, raiva, etc., a outros conjuntos de objetos, e o indivíduo passar a reagir sentimentalmente a estes. Um 
indivíduo que é capaz de se imaginar em uma situação de risco extremo não vivenciada, pode agora experenciar uma outra forma de medo-algo, talvez, como pânico ou terror. Um indivíduo que é capaz agora de se orientar por antecipação a uma experiência deflagradora de medo, pode passar a experimentar outra forma de medo-algo, talvez, como ansiedade.

Mas, além disso, o processo pode passar a ser complexo a ponto de gerar novas emoções e experiências valorativas, e não apenas variações das mesmas. Reflexão e uso de conceitos valorativos podem permitir que tais indivíduos experenciem novas reações sentimentais resultantes de um processo reflexivo que envolva conjunções de experiências sentimentais valorativas bem consolidadas na psicologia de um indivíduo, redirecionadas a outras relações com o mundo. Assim, um indivíduo pode combinar, através de um exercício reflexivo, suas experiências consolidadas de medo e tristeza a outros estados de coisas, promovendo um redirecionamento daquelas a estes. O resultado disso, na forma de reações sentimentais, pode ser, novamente, uma espécie de "amálgama" de várias experiências valorativas redirecionadas e, assim, representar uma experiência valorativa nova, distinta e agora indissociável em seus elementos componentes.

A história que acabamos de contar entende a complexidade de emoções como resultado de representações sentimentais de ordem superior, supervenientes a outras emoções de ordem inferior (e seus respectivos conteúdos representacionais), redirecionadas a outros objetos, indivíduos, estados de coisas. De posse deste esquema, o nosso sentimentalista pode agora explicar emoções de ordem superior como orgulho, indignação (moral), etc.

O sentimentalista pode agora dizer, por exemplo, sobre o orgulho, que esta é uma emoção de ordem superior, superveniente a outras emoções redirecionadas a descrições (não-valorativas) de outros estados de coisas. Orgulho parece envolver um sentimento positivo direcionado a um objeto ou propriedade pertencente ao próprio indivíduo (ou com os quais ele se identifica intimamente) que é tomado como valoroso. Assim, nosso sentimentalista pode dizer que orgulho é um sentimento de ordem superior direcionado a algo valoroso associado ao eu. O nosso sentimentalista pode explicar este algo valoroso, introduzindo um conceito e/ou juízo valorativo exatamente como fez antes: valores 
devem ser explicados em bases sentimentais. Sendo assim, orgulho não seria nada mais do que uma nova reação sentimental, de ordem superior, resultante de um processo reflexivo que toma como objeto outras experiências sentimentais valorativas (no caso do orgulho, experiências que provavelmente envolvam emoções de alegria, admiração, deleite, amor, etc. e seus valores associados) redirecionadas a uma descrição de novo objeto (no caso do orgulho, uma referência ao eu). Assim, citando um famoso exemplo, uma casa confortável pode produzir alegria em um indivíduo e, quando essa alegria é redirecionada ao pensamento de pertencimento da casa ao eu, ela pode se tornar objeto de orgulho. Vale notar que orgulho, neste modelo, é um resultado emocional novo e distinto, uma reação sentimental resultante de um processo reflexivo de redirecionamento de experiências valorativas prévias a novos objetos, indivíduo, estados de coisas. O conteúdo valorativo do orgulho não é dado individualmente nem pelas outras emoções que toma como objeto, nem pela descrição do estado de coisas ao qual tais emoções são redirecionadas. O conteúdo valorativo é o resultado "amalgamado" da tomada conjunta de ambos e da reação sentimental equivalente.

\section{Emoções e valores morais}

Emoções morais impõem uma dificuldade adicional oriunda da ideia disseminada de que não é possível descrever a dimensão moral em termos valorativamente neutros e de que, se há valores envolvidos, estes devem já ser morais. Como o nosso sentimentalista pode responder a isso?

O sentimentalista deve defender que, como resultado de um processo reflexivo, juízos valorativos morais-gerados por reações emocionais (sentimentais)—são supervenientes a juízos valorativos mais básicos não-morais-gerados por reações emocionais (sentimentais) não-morais — redirecionados a descrições (não-valorativas) de relações de estados de coisas do mundo. Assim, valores morais são o resultado reflexivo das reações sentimentais do indivíduo quando ele passa a redirecionar vários dos seus valores egocêntricos, comunitários e sociais a descrições de estados de coisas sobre relações universais, imparciais e categóricas acerca da interação entre indivíduos. ${ }^{37}$ As reações emocionais (sentimentais) resultantes desse processo reflexivo são as reações 
geradoras de experiência moral e, por extensão, da possibilidade de aquisição de conceitos e juízos morais.

Essa é uma história progressiva, desenvolvimentista sobre o processo de experimentação e aquisição de conceitos e juízos morais. ${ }^{38}$ Como dissemos acima, ela pressupõe que um indivíduo inicia sua aquisição de competências valorativas através de suas reações sentimentais básicas relacionadas a necessidades vitais. Concomitantemente a isso, ele passa a interagir com outros indivíduos e a estender suas reações sentimentais a estes. Em algum momento neste processo, ele adquire ou desenvolve sofisticação reflexiva a ponto de atribuir as mesmas capacidades mentais que possui àqueles com quem interage. Neste momento, ele torna-se capaz de se colocar na situação daqueles com quem interage e compartilhar seus sentimentos (possivelmente internalizando as reações negativas e positivas dos demais sobre si e projetando as suas sobre os demais). Assim, passa a ser possível a este indivíduo adquirir uma espécie de senso comunitário que expande seus laços, identificando-se com alguma espécie de círculo de relações compartilhadas (que pode ainda ser amplamente familiar ou estendido àqueles com quem interage direta e continuamente). Em um passo adicional nessa progressão, o indivíduo é capaz de desenvolver algum tipo de espírito comum, que é um redirecionamento de sua reação sentimental associada a seu círculo comunitário de relações individualizadas e personalizadas a relações formais com indivíduos estranhos. Isso, obviamente, pode ocorrer em vários níveis progressivos. Mas, neste momento, podemos dizer que o indivíduo passa a adquirir uma perspectiva valorativa social. Ele é capaz de redirecionar seus valores egocêntricos e comunitários a uma perspectiva que se aplica a um espaço comum que envolve relações de cooperação e mecanismos de produção de bens, organizados segundo critérios de distribuição de deveres e direitos, como parte de um sistema estruturado em torno de alguma concepção unificadora de sociedade - que pode variar desde laços históricos e culturais, convenções e idiomas comuns, passando por tradições consuetudinárias e valores de outra natureza (como religiosos) até uma visão formal e legal de demarcação territorial ou simplesmente a ocupação de um mesmo espaço físico.

Em cada um desses passos, valores dados por reações emocionais (sentimentais) estão envolvidos: pessoais, familiares, comunitários, sociais. Mas nenhum destes parece ser ainda propriamente moral. Valores morais parecem ser obtidos apenas quando o 
indivíduo passa a estabelecer novas relações entre seus valores mais circunscritos e outros estados de coisas descritos de uma perspectiva universal, imparcial e categórica; quando o indivíduo passa a redirecionar aqueles a uma descrição de estados de coisas desta perspectiva. É, então, apenas quando o indivíduo tem reações sentimentais a tal conjunção de valores e perspectivas que ele passa a ter as condições necessárias para adquirir competência valorativa moral e sua respectiva posse de conceitos.

Essa não é uma história nova, obviamente. Ela é essencialmente uma história Humeana. Todos os passos naquela progressão são contingentes. Nenhum deles é necessário no desenvolvimento de um indivíduo. Eles são necessários apenas para a aquisição de conceitos e competências valorativos (nos seus mais variados níveis). Segundo a tese sentimentalista em questão, um indivíduo que não é capaz de tais reações sentimentais resultantes de tais processos reflexivos não é capaz de possuir conceitos e adquirir competências egocêntricas, comunitárias, sociais e morais. ${ }^{39}$

Neste momento, uma possível confusão deve ser desfeita. Ao redirecionar seus valores egocêntricos, comunitários e sociais a uma perspectiva universal, imparcial e categórica, submetendo-os a esta perspectiva, o indivíduo não estaria já de posse de conceitos morais e, consequentemente, formulando juízos morais? Para o nosso sentimentalista, não. Da mesma forma que dissemos acima que o conteúdo propriamente valorativo do orgulho só é dado com a reação sentimental resultante de um processo reflexivo, o mesmo deve valer para o caso moral. O conteúdo valorativo moral não é dado individualmente nem pelos valores egocêntricos, comunitários e sociais do indivíduo, nem pela perspectiva universal, imparcial e categórica. É apenas quando o indivíduo toma ambos em conjunção como objeto de reflexão e reage sentimentalmente a tal conjunção que ele propriamente tem uma experiência valorativa moral-que é, mais uma vez, uma experiência valorativa emocional nova e distinta, uma "amálgama" entre perspectivas valorativas prévias agora redirecionadas a um novo estado de coisas. Sendo assim, 'universal', 'imparcial' e 'categórico' não possuem conteúdo valorativo moral sem uma resposta sentimental. 'Universal', 'imparcial' e 'categórico' devem ser compreendidas como relações especificáveis primariamente em termos valorativamente neutros. São descrições de relações do mundo que, por si só, não possuem conteúdo valorativo. 
Assim, o sentimentalista pode, por exemplo, sobre indignação (moral), dizer que esta é uma emoção de ordem superior (provavelmente relacionada a alguma manifestação de raiva) que toma como objeto uma gama variada de outros valores (não-morais) do indivíduo redirecionados a outros estados de coisas, tomados de uma perspectiva universal, imparcial e categórica. Supondo que o conceito que melhor especifica o objeto formal da indignação moral é a injustiça e se injustiça é caracterizável fundamentalmente em termos de algum tipo de iniquidade ${ }^{40}$ então o sentimentalista deve dizer que a injustiça — entendida como iniquidade de uma perspectiva universal, imparcial e categórica—só adquire propriamente conteúdo valorativo moral quando o indivíduo é capaz de reagir sentimentalmente a tais relações vistas de tal perspectiva. Neste sentido, da mesma forma que vimos acima, o sentimentalista deve dizer que há uma descrição neutra valorativamente de 'injustiça', que é o objeto da reação sentimental do indivíduo. ${ }^{41}$ Assim, de modo similar ao esquema anterior, podemos dizer agora que:

Julgar que Xé moralmente errado é julgar que é adequado sentir indignação em relação a X; em que sentir indignação é caracterizado através de seu objeto formal, injustiça ${ }^{*}{ }^{42}$

Com base neste modelo, podemos agora conceber a extensão para outras emoções morais. Se a emoção de indignação moral for uma emoção moral primária, o sentimentalista pode agora, por exemplo, dizer que a emoção moral de culpa é dependente da emoção de indignação moral, como algo que envolve a internalização da indignação dos meus pares diante do meu ato de injustiça. Assim, um esquema similar àquele pode ser formulado para a culpa, com a exceção de que esta emoção seria uma emoção moral derivada de uma emoção moral mais básica (indignação), que figura como um de seus objetos. ${ }^{43}$

\section{Coda}

Voltemos agora, para finalizar nossa discussão, ao problema com o qual iniciamos. Uma vez que nem toda manifestação de medo, de orgulho e de indignação moral será adequada, e que o sentimentalista foi capaz de fornecer uma caracterização não-circular de sentimentos (em relação aos conceitos que figuram como seus objetos formais), ele pode 
agora mais claramente responder ao problema da recalcitrância. Este problema surge tipicamente quando sentimos, por exemplo, medo, orgulho, indignação moral que julgamos, de uma perspectiva de ordem superior, inadequados. As experiências do medo, do orgulho e da indignação moral são reações sentimentais que nos engajam valorativamente com uma descrição (não-valorativa) de perigo, uma descrição de objetos valorosos relacionados ao eu, uma descrição (não-moral) de injustiça, respectivamente. Essas reações sentimentais podem ser recalcitrantes e persistirem diante de juízos contrários sobre sua adequação em tais situações. Nestes casos, ainda que essas experiências emocionais básicas nos engajem valorativamente com o mundo, elas não envolvem conceitos e juízos valorativos. Elas possuem, por assim dizer, um status valorativo prima facie. Podem, portanto, ser ditas inadequadas de uma perspectiva de ordem superior, na qual conceitos e juízos valorativos passam a ser empregados. A mesma história pode agora ser contada para emoções cada vez mais complexas (e suas respectivas experiências valorativas), que envolvem níveis progressivamente mais elevados de reflexão.

Assim, a história que acabamos de contar tentou mostrar o que uma tese que pretenda ser sentimentalista, coerente sobre a relação entre valor e emoção e plausível como teoria das emoções deve sustentar. ${ }^{44}$ 


\begin{abstract}
Notas
${ }^{1}$ Professor Adjunto de Filosofia da Universidade Federal de Minas Gerais (UFMG), Belo Horizonte, M. G., Brasil. e-mail: lmribeiro@ufmg.br
\end{abstract}

${ }^{2}$ Cf. D’Arms \& Jacobson (2003) e Deigh (1994), embora o último não use o termo 'recalcitrância'.

${ }^{3}$ Sentimentalismo, como entendido aqui, é uma tese que atribui prioridade conceitual a sentimentos na caracterização de emoções e na explicação da aquisição de conceitos valorativos. Por 'sentimento' entendemos o mesmo que o termo 'feeling' na literatura de língua inglesa. É comum também, nesta literatura, o termo 'sentiment', que, para alguns autores, significa uma disposição para experenciar emoções (Cf. Prinz 2007; 2004). No que se segue, ao usar 'sentimento', não faremos distinção entre os significados possíveis de 'feeling' e 'sentiment'. Como também ficará claro, sentimentos não são meras sensações.

${ }^{4}$ Cf. Lazarus (1991, 122). Tais objetos são chamados por Lazarus de 'core relational themes'. Estes são aquilo que essencialmente distingue uma emoção de outra através da relação que existe entre o ambiente e o bem-estar do indivíduo, que é avaliada (appraised) através de juízos de modo multidimensional. Lazarus é um dos expoentes do grupo de teses judicativas chamadas de appraisal theories (daqui em diante $A T s$ ). Voltaremos a este tipo de teoria.

${ }^{5}$ Cf. Kenny $(1963,187$ ss.).

${ }^{6}$ Mesmo teorias neo-Jamesianas das emoções reconhecem, ora explicitamente (como Prinz 2004), ora implicitamente (como Damasio 1994), a necessidade de acomodar algo da tese de Kenny.

7 'Supostamente radical' porque é contestável que Hume a defenda. Hume fala de critérios de correção de emoções e não é claro que tais critérios sejam integralmente fornecidos por emoções. Ele diz, por exemplo, (de maneira mais enfática na segunda Investigação do que no Tratado) que, embora o julgamento de caracteres e ações como louváveis ou censuráveis seja dependente de um "senso ou sentimento interno, que a natureza tornou universal em toda a espécie" (Hume 1975, 172-173), deve-se reconhecer que há frequentemente algo mais em várias distinções valorativas (estéticas e morais, em particular). Isso é o caso porque "in order to pave the way for such a sentiment, and give a proper discernment of its object, it is often necessary, we find, that much reasoning should precede, that nice distinctions be made, just conclusions drawn, distant comparisons formed, complicated relations examined, and general facts fixed and ascertained. Some species of beauty, especially the natural kinds, on their first appearance, command our affection and approbation; and where they fail of this effect, it is impossible for any reasoning to redress their influence, or adapt them better to our taste and sentiment. But in many orders of beauty, particularly those of the finer arts, it is requisite to employ much reasoning, in order to feel the proper sentiment; and a false relish may frequently be corrected by argument and reflection. There are just grounds to conclude, that moral beauty partakes much of this latter species, and demands the assistance of our intellectual faculties, in order to give it a suitable influence on the human mind." (Hume 1975, 172-173; ver também Appendix I) ("a fim de preparar o terreno para tal sentimento, e permitir discernimento adequado de seu objeto, parece-nos frequentemente necessário que bastante raciocínio deva precedê-lo, que distinções refinadas sejam feitas, conclusões corretas sejam extraídas, comparações remotas formadas, relações complicadas examinadas, e fatos gerais fixados e verificados. Algumas formas de beleza, especialmente os tipos naturais, comandam nosso afeto e aprovação à sua primeira aparição; e quando falham em produzir este efeito, é impossível para qualquer raciocínio remediar sua influência ou adaptá-las melhor ao nosso gosto e sentimento. Mas no caso de muitas outras formas de beleza, particularmente aquelas das belas artes, é necessário empregar bastante raciocínio a fim de experimentar o sentimento adequado; e um falso deleite pode frequentemente ser corrigido por argumento e reflexão. Há bases seguras para se concluir que a beleza moral compartilha muito desta última forma e necessita do auxílio de nossas faculdades intelectuais para lhe conferir a influência adequada na mente humana." Tradução nossa.)

${ }^{8}$ Adam Smith pode ser considerado o precursor dessa tendência, ao introduzir explicitamente a noção de "adequação" (propriety) de emoções. Contemporaneamente, isso se reflete em autores como D'Arms \& 
Jacobson (2000), Blackburn (1998) e Gibbard (1990). Com ressalvas, McDowell (1998) poderia ser incorporado ao grupo.

9 “(...) As crenças nas quais emoções estão baseadas incluem proeminentemente nossas crenças valorativas, nossas crenças sobre o que é bom ou mau, valoroso ou sem valor, útil ou danoso." (Tradução nossa.) Ver também Nussbaum (2001), onde ela descreve emoções como juízos valorativos de segunda-ordem direcionados a aparências (entendidas como juízos básicos não justificados).

10 “(...) emoções essencialmente envolvem as habilidades de conceitualizar e valorar.” (Tradução nossa.)

11 “O cerne de toda emoção são seus juízos valorativos, suas avaliações de ganhos e perdas, suas condenações de ofensas e sua exaltação de virtude, seus juízos frequentemente Maniqueístas de "bem" e "mal", "certo" e "errado"." (Tradução nossa.)

12 “(...) emoções são engajamentos com o mundo, não meros sentimentos fechados em si mesmos, e, neste sentido, tentei especificar esta perspectiva insistindo, através de algo como um slogan, que emoções são juízos. Quero dizer com isso, obviamente, que emoções são juízos valorativos (...).” (Tradução nossa.)

13 “(...) o medo (...) é um engajamento com o mundo, não apenas um "sentimento" fechado em si mesmo. Ele é sobre algo que ameaça, algo que envolve perigo. (...) o medo não é medo a menos que seja sobre algum perigo percebido no mundo.” (Tradução nossa.)

${ }^{14}$ Recentemente, Solomon (2007, 204ss.) propôs incluir à natureza das emoções sentimentos, fisiologia e alterações corporais: "I claim that judgments are essential to emotion, although I no longer say, as I did those many years ago, that feelings and physiology are irrelevant. I now agree with the neo-Jamesians that they are also essential to emotion (...)." (Solomon 2007, 205) ("Defendo que juízos são essenciais a emoções, embora eu não mais diga, contrariamente ao que disse muitos anos atrás, que sentimentos e fisiologia são irrelevantes. Eu agora concordo com os neo-Jamesianos que estes são também essenciais a emoções." Tradução nossa.) Mas não é claro que Solomon tenha conseguido unificar todos aqueles elementos em sua tese (sobretudo pela persistência na defesa da centralidade do elemento judicativo).

${ }^{15}$ Há, assim, um vasto campo de teses judicativas. Para algumas delas, os juízos são puramente factuais (e não valorativos). (Ver Reizensein 2009 para uma discussão e defesa.) ATs, por outro lado, postulam juízos valorativos. Segundo a maioria destas, emoções são processos (que envolvem componentes mentais, somáticos e comportamentais, além de manifestações e expressões multifacetadas) causados e unificados por juízos valorativos. Dentre os principais defensores de ATs estão Lazarus (1991), Johnson-Laird \& Oatley (1992; 1987), Frijda (1993), Scherer (2004).

${ }^{16}$ Solomon, por exemplo, diz que: “(...) feelings [do not] constitute or define the emotion (...). Feeling is the ornament of emotion, not its essence" $(1976,159)$. (“(...) sentimentos [não] constituem ou definem uma emoção (...). O sentimento é o ornamento da emoção, não a sua essência." Tradução nossa.) Nussbaum (2001, 56ss.) defende algo similar. Uma exceção na literatura judicativa é Scherer (2004), para quem sentimentos cumprem um papel fundamental de monitoração e integração dos vários componentes de um processo emocional.

17 “[Emoções] possuem, elas mesmas, um conteúdo cognitivo; elas estão intimamente relacionadas a crenças ou juízos sobre o mundo de forma tal que a remoção da crença relevante removerá não apenas a razão para a emoção, mas também a própria emoção. A crença é a base necessária e "fundamento" da emoção. Ela pode até mesmo ser considerada uma parte constituinte da própria emoção. (...) Isto implica (...) que [por exemplo, em um caso de raiva], se eu descobrir que a minha crença é falsa — que o mal aparente não ocorreu de fato-irei, descartando a minha crença falsa, deixar de ficar com raiva. Se algum resíduo de sentimento doloroso permanece, ele não será mais considerado raiva, mas, em vez disso, um resíduo de irritação ou excitação irracional.” (Tradução nossa.)

${ }^{18}$ Por exemplo, Greenspan (1988). Para críticas, ver D’Arms \& Jacobson (2003) e Deigh (1994). 
${ }^{19}$ Foot torna precisa a objeção da circularidade, dizendo, acerca de Hume, que: "Hume was, I think, making a mistake when he tried to explain what it meant to say that an action or quality was virtuous in terms of a special feeling; for the explanation of the thought comes into the description of the feeling, not the other way round" $(1978,76)$. ("Hume, penso, cometeu um erro quando tentou explicar o que significava dizer que uma ação ou qualidade é virtuosa em termos de um sentimento especial; pois a explicação do pensamento aparece na descrição do sentimento, não o contrário." Tradução nossa.)

\section{${ }^{20}$ Cf. James (1884), Damasio (1994), Prinz (2004).}

${ }^{21} \mathrm{Na}$ verdade, nosso ponto central não depende de uma resposta a essa questão. Embora a formulação da tese sentimentalista tenha sido apresentada através de uma análise não-redutiva (por esta soar mais plausível), a formulação é compatível com uma análise redutiva que descrevesse em termos não-normativos o conceito de adequação.

${ }^{22}$ Assim como não está excluída uma posição cética sobre a fundamentação de tais critérios de adequação.

23 "Ter um sentimento direcionado a algo é pensar com sentimento, de modo que seus sentimentos emocionais são direcionados ao objeto do seu pensamento. Assim, por exemplo, se eu sinto nojo de pudim, meus sentimentos de nojo são direcionados a alguma propriedade ou característica percebida ou imaginada do pudim — talvez a sua viscosidade — que eu apreendo como nojenta.” (Tradução nossa.)

24 "Quando uma emoção é direcionada ao seu objeto, isto é um tipo de sentimento direcionado ao objeto. O objeto pode ser uma coisa ou uma pessoa, um estado de coisas, ou uma ação ou evento: quando você teme um leão, o objeto do seu medo é uma coisa, que possui certas propriedades determinadas (dentes afiados, talvez), que explicam por que você o teme." (Tradução nossa.)

25 “(...) para saber o que alguém está sentindo, não é preciso-o que é impossível—de algum modo compartilhar o seu peculiar, imediato e "privilegiado" método de acesso; tudo o que se precisa ser capaz de fazer é responder a questão, “o que ele está sentindo?”.” (Tradução nossa.)

26 “Quando pensamos sobre sentimentos, e os reconhecemos como o que são, estamos empregando um conjunto comum de conceitos, compartilhado com outros, e podemos pensar e falar sobre como o outro está sentindo do mesmo modo que podemos pensar e falar sobre como estamos nos sentindo." (Tradução nossa.)

27 "Para cada tipo de emoção, haverá uma ampla natureza qualitativa típica desses sentimentos. Mas experiências emocionais individuais podem variar vastamente em como são sentidas. Qualquer sugestão de que nossos sentimentos emocionais direcionados a algo podem ser compreendidos ou analisados em termos mais simples (tais como atração ou aversão, prazer ou aflição, sentir conforto ou desconforto, avaliações positivas ou negativas em alguma escala de classificação) deve ser fortemente resistida." (Tradução nossa.)

${ }^{28}$ Goldie não está sozinho nessa empreitada. Ver Kriegel (2015, cap.4) para a defesa de uma proposta similar, explicitamente influenciada por Goldie. A ideia de sentimentos com conteúdo representacional também está presente em Charland (1995) e Panksepp (1982), embora estes pareçam compreender tal conteúdo em termos não-cognitivos.

29 “Agora (...) Irene é capaz de perceber e pensar no gelo de uma forma nova. A sua crença "este pedaço de gelo é perigoso", embora talvez verbalmente expressa da mesma maneira que antes, é agora uma crença com um conteúdo diferente. Além disso, antes ela acreditava que o gelo é perigoso sem sentir nada; agora ela acredita sentindo - com um sentimento de medo. Assim, há uma mudança tanto de atitude quanto uma mudança de conteúdo." (Tradução nossa.)

${ }^{30}$ Goldie não dá esse passo além porque ele parece entender que o conteúdo cognitivo é valorativo. Neste sentido, Goldie defende uma versão da tese judicativa (embora uma tal que sentimentos são tão essenciais quanto juízos valorativos para a caracterização de emoções). 
${ }^{31}$ Parte do caráter valorativo da experiência emocional deve ser constituído pela valência das emoções, experenciadas como positivas ou negativas. Estas características são, por sua vez, comumente explicadas em termos de perfil hedônico. Neste sentido, prazer e desconforto (desprazer ou dor), embora estados afetivos, seriam sensações componentes de emoções, mas não propriamente emoções.

${ }^{32}$ Mas ao falar de situações de risco, de obstáculos, etc., isso não significa falar de uma propriedade relacional, explicável através de uma relação de dependência a algum fim (já de conteúdo valorativo) presente no indivíduo? Sentimentalistas devem dizer que, se tais fins possuem conteúdo valorativo, eles já são constituídos por emoções como sentimentos. Por exemplo, Izard (1977) (que não é um sentimentalista) defende alguma forma de interesse como uma emoção básica. Uma apropriação sentimentalista dessa proposta, diria, então, que o objeto do medo, por exemplo, já envolveria uma apreensão valorativa do mundo dada por interesses básicos na forma de sentimentos. Mas vários fins relacionados a situações de risco, de obstáculos, etc., não parecem envolver conteúdo valorativo. Por exemplo, as capacidades de um indivíduo satisfazer suas necessidades de se alimentar, copular ou mesmo se manter vivo não parecem implicar, por si só, valor. Neste sentido, o sentimentalista pode dizer que é apenas quando tais fins vitais geram sentimentos associados que uma mera relação orgânica é transformada em uma experiência valorativa.

${ }^{33}$ Vale dizer que 'perigo' (como objeto formal) é uma propriedade abstrata. O conceito 'perigo' é resultado de um processo de generalização e abstração que envolve um conjunto de propriedades. Mas é certamente possível reagir a situações concretas de perigo sem usar o conceito 'perigo'. Deigh $(1994,840)$ defende algo similar ao distinguir entre ser sensível a algo e possuir o conceito deste algo: "Many people are sensible of sharps and flats, for instance, though they have no concept of half steps in a diatonic scale." ("Muitas pessoas são sensíveis a sustenidos e bemóis, embora não possuam nenhum conceito de meio tom em uma escala diatônica." Tradução nossa.) Para ser sensível a uma propriedade, basta ser capaz de detectá-la e discriminá-la.

${ }^{34}$ Embora não haja espaço aqui para uma taxonomia das emoções, pode-se dizer algo mais a respeito. Nossa tese sentimentalista não depende de uma adesão à tradicional teoria das emoções básicas. Não obstante, o sentimentalista poderia facilmente adotar esta teoria. Emoções básicas são normalmente formuladas em dois modelos: como famílias distintas de emoções (que variam em antecedentes causais, fisiologia e expressão corporal); como um grupo de emoções distintas específicas que, quando combinadas entre si, geram novas emoções. Ekman (1992) e Plutchik (1980), respectivamente, defendem esses modelos. Ambos baseiam-se em uma história adaptativa evolucionista para explicar a origem das emoções. A lista de Ekman (alegria, tristeza, raiva, medo, nojo e surpresa) extrai evidência de estudos comparativos de expressões faciais universais. Todas as demais emoções são variações dentro de cada uma daquelas famílias. Plutchik, por sua vez, pensa que há oito emoções básicas específicas (alegria, aceitação, medo, surpresa, tristeza, nojo, raiva, antecipação), que são respostas a um conjunto de problemas e comportamentos adaptativos. As demais emoções são resultados da combinação (em díades e tríades) das emoções básicas. Por exemplo, medo e tristeza geram desespero; alegria e surpresa, deleite; surpresa e raiva, ultraje; etc. Como veremos, a nossa história sentimentalista incorporará elementos tanto de Ekman quanto de Plutchik. Para uma crítica relevante da teoria das emoções básicas, ver Ortony \& Turner (1990).

\section{${ }^{35}$ Cf. Ekman (1992, 175).}

${ }^{36}$ A experiência valorativa primitiva em questão pode até mesmo ser não-conceitual. Johnson-Laird \& Oatley (1992) defendem que emoções básicas são não-proposicionais e, tal como parece, também nãoconceituais. Ver também Izard (1977).

${ }^{37}$ Relações universais, imparciais e categóricas que versam sobre a interação entre indivíduos podem ser entendidas como fornecendo uma definição formal de moralidade, baseada em uma concepção ordinária desta. Essa definição não deve, porém, ser entendida como fixa. Assim, relativistas de todos os tipos (subjetivistas, comunitários, sociais) não estão necessariamente excluídos. Basta admitir que, se o conceito de moralidade for dado, por exemplo, por relações sociais, então basta possuir sentimentos sociais para a posse de conceitos e formulação de juízos morais.

${ }^{38}$ Como tal, está sujeita a objeções empíricas. 


\begin{abstract}
${ }^{39}$ Mas nada disso implica que um indivíduo deva racionalmente aderir à perspectiva moral. A história sentimentalista aqui contada diz respeito ao desenvolvimento de competências valorativas. Ela é, assim, compatível tanto com teses anti-racionalistas quanto com teses racionalistas sobre o conceito de moralidade. $\mathrm{Na}$ versão racionalista, um indivíduo deve racionalmente conduzir sua vida pela perspectiva dos sentimentos morais. Isso permite agora explicar o sentido de 'categórico' pressuposto em nossa definição formal de moralidade. 'Categórico' aqui não significa 'autoridade racional', mas meramente 'inescapabilidade'. Assim, um juízo moral aplica-se a um indivíduo, quer isto seja ou não de seu interesse particular. Mas isso, por si só, não implica autoridade racional de tal juízo. Pode-se dizer que há também um sentido associado de inescapabilidade vinculado a juízos comunitários e sociais (em cujo caso categoricidade não seria algo distintivo de juízos morais). Porém, nestes dois contextos, algum tipo de adesão do indivíduo parece ser uma condição necessária para a aplicabilidade dos respectivos juízos. No caso moral, por outro lado, a aplicabilidade dos juízos não depende de adesão. Para uma discussão dos vários sentidos de ‘categórico', ver Brink (1997).
\end{abstract}

${ }^{40}$ Injustiça é provavelmente uma propriedade multiplamente realizável. Mas este detalhe não deve afetar o argumento. Basta supor que iniquidade é uma das bases possíveis de realização de injustiça.

${ }^{41}$ Diferentes indivíduos terão reações distintas a distintas formas de inequidade. Alguns priorizarão distribuição de bens materiais ou primários, outros, níveis de liberdade, ainda outros, bens instrumentais em relação a níveis de felicidade ou satisfação de preferências, etc. Essa variação entre as reações sentimentais deve ser preservada, pois nenhuma delas parece ser definidora de iniquidade. Estabelecer os critérios de adequação da iniquidade é uma tarefa propriamente normativa (e pressupomos que a nossa história sentimentalista é compatível com uma variedade de respostas possíveis neste aspecto).

42 Para o nosso sentimentalista, 'moralmente errado' deve ser um conceito que se refere às condições de adequação de um conjunto de emoções morais (negativas). Uma ideia similar é desenvolvida por Prinz (2007, caps. 2 e 3$)$.

${ }^{43}$ Gibbard (1990) defende algo nestes termos.

44 Este artigo é resultado de pesquisa que obteve auxílio financeiro do Conselho Nacional de Desenvolvimento Científico e Tecnológico - $\mathrm{CNPq}$ - Brasil, ao qual sou grato. Agradeço também às audiências em palestras proferidas na Universidade Federal de Minas Gerais, na Universidade Federal de Santa Maria e na FAJE - Faculdade Jesuíta de Filosofia e Teologia, de cujas discussões, relacionadas a versões anteriores deste artigo, eu me beneficiei grandemente. 


\section{Referências}

Blackburn, Simon. Ruling Passions: A Theory of Practical Reasoning. Oxford: Clarendon Press, 1998.

Brink, David O. "Kantian Rationalism: Inescapability, Authority, and Supremacy". In Cullity, G. and Gaut, B. Ethics and Practical Reason. Oxford: Clarendon Press, 1997.

Charland, Louis C., "Feeling and Representing: Computational Theory and the Modularity of Affect". Synthese 105, No.3 (1995): 273-301.

Damasio, Antonio R. Descartes' Error: Emotion, Reason and the Human Brain. London: Papermac, 1994.

D'Arms, Justin and Jacobson, Daniel. "The Significance of Recalcitrant Emotion (or Antiquasijudgmentalism)". In Hatzimoysis, A. (ed.). Philosophy and the Emotions. Cambridge, UK: Cambridge University Press, 2003.

."Sentiment and Value". Ethics 110, No.4 (2000): 722-748.

Deigh, John. "Cognitivism in the Theory of Emotions". Ethics 104, No.4 (1994): 824-854.

Ekman, Paul. “An Argument for Basic Emotions”. Cognition and Emotion 6, No.3/4 (1992): 169200.

Foot, Philippa. Virtues and Vices and Other Essays in Moral Philosophy. Oxford: Blackwell, 1978.

Frijda, Nico H. "The Place of Appraisal in Emotion". Cognition and Emotion 7, No.3/4 (1993): 357-387.

Gibbard, Allan. Wise Choices, Apt Feelings: A Theory of Normative Judgment. Cambridge, Mass.: Harvard University Press, 1990.

Goldie, Peter. "Getting Feelings into Emotional Experience in the Right Way". Emotion Review 1, No.3 (2009): 232-239.

."Emotions, Feelings and Intentionality". Phenomenology and the Cognitive Sciences 1 (2002): 235-254.

. The Emotions: a Philosophical Exploration. Oxford: Clarendon Press, 2000.

Greenspan, Patricia. Emotions and Reasons: An Inquiry into Emotional Justification. London: Routledge, 1988.

Hume, D. An Enquiry Concerning the Principles of Morals. L. A. Selby-Bigge (ed.), 3rd edition revised by P. H. Nidditch. Oxford: Clarendon Press, 1751/1975.

Izard, Carroll E. Human Emotions. New York: Springer Science, 1977.

James, William. “What Is An Emotion?”. Mind 9, No.34 (1884): 188-205. 
Johnson-Laird, P. N. and Oatley, Keith. "Basic Emotions, Rationality, and Folk Theory". Cognition and Emotion 6, No.3/4 (1992): 201-223.

. "Towards a Cognitive Theory of Emotions". Cognition and Emotion 1, No.1 (1987): 2950.

Kenny, Anthony. Action, Emotion and Will. London: Routledge, 1963.

Kriegel, Uriah. The Varieties of Consciousness. Oxford: Oxford University Press, 2015.

Lazarus, Richard S. Emotion and Adaptation. Oxford: Oxford University Press, 1991.

McDowell, John. "Values and Secondary Qualities". In Mind, Value, and Reality, Cambridge, Mass.: Harvard University Press, 1998.

Nussbaum, Martha. C. Upheavals of Thought: The Intelligence of Emotions. Cambridge: Cambridge University Press, 2001.

Love's Knowledge: Essays on Philosophy and Literature. Oxford: Oxford University Press, 1990.

Ortony, Andrew and Turner, Terence J. "What's Basic about Basic Emotions?". Psychological Review 97, No.3 (1990): 315-331.

Panksepp, Jaak. "Toward a General Psychobiological Theory of Emotions". The Behavioral and Brain Sciences 5, No.3 (1982): 407-467.

Plutchik, Robert. Emotion: A Psychoevolutionary Synthesis. New York: Harper \& Row, 1980.

Prinz, Jesse J. The Emotional Construction of Morals. Oxford: Oxford University Press, 2007.

. Gut Reactions: A Perceptual Theory of Emotion. Oxford: Oxford University Press, 2004.

Reisenzein, Rainer. "Emotions as Metarepresentational States of Mind: Naturalizing the Beliefdesire Theory of Emotion". Cognitive Systems Research 10, No.1 (2009): 6-20.

Scherer, Klaus R. "Feelings Integrate the Central Representation of Appraisal-driven Response Organization in Emotion". In Mantead, A. S. R., Frijda, N., Fischer, A. (eds.). Feelings and Emotions: The Amsterdam Symposium. Cambridge: Cambridge University Press, 2004.

Solomon, Robert C. True to Our Feelings: What Our Emotions Are Really Telling Us. Oxford: Oxford University Press, 2007.

. The Passions. New York: Anchor Press/Doubleday, 1976. 